Full Name: Michael A. Greig

Affiliation: Human Factors Engineering Lab, Department of Mechanical and Industrial Engineering, Ryerson University

Current Postal Address: 1-143 Gilmour Avenue, Toronto, ON, M6P 3B2

Phone: 647-200-6453

Email: m2greig@ryerson.ca

ORCiD: orcid.org/0000-0001-6354-8581

*Corresponding author

Full Name: Judy Village

Affiliation: Human Factors Engineering Lab, Department of Mechanical and Industrial Engineering, Ryerson University

Current Postal Address: \#212-123 West $1^{\text {st }}$ Street. North Vancouver, BC, Canada, V7M 0E5

Phone: 604 787-9078

Email: jvillage@shaw.ca

Full Name: Shane M. Dixon

Affiliation: Human Factors Engineering Lab, Department of Mechanical and Industrial Engineering, Ryerson University

Current Postal Address: Office of Research Services, Wilfrid Laurier University, 75 University Avenue

West, Waterloo, ON N2L 3C5, Canada

Phone:

Email: sdixon@wlu.ca

Full Name: Filippo A. Salustri

Affiliation: Department of Mechanical and Industrial Engineering, Ryerson University

Current Postal Address: Department of Mechanical and Industrial Engineering, Ryerson University, 350

Victoria St, Toronto, Canada, M5B 2K3

Phone:

Email: salustri@ryerson.ca

ORCiD: orcid.org/0000-0002-3689-5112

Full Name: W. Patrick Neumann

Affiliation: Human Factors Engineering Lab, Department of Mechanical and Industrial Engineering, Ryerson University

Current Postal Address: Human Factors Engineering Lab, Department of Mechanical and Industrial

Engineering, Ryerson University, 350 Victoria St, Toronto, Canada, M5B 2K3

Phone:

Email: pneumann@ryerson.ca

ORCiD: orcid.org/0000-0002-1560-3870

Research affiliation:

Human Factors Engineering Lab, Department of Mechanical and Industrial Engineering, Ryerson

University

Article Word Count: Total in manuscript 11,323; manuscript body $-7,098$; appendix $-1,771$ 


\section{Assessing human factors and ergonomics capability in organizations - The Human Factors Integration Toolset}

Acknowledgements:

The authors would like to thank Don Patten, Asad Mohani, and the participants from the workshops and BlackBerry Limited for their time and contributions.

Funding:

This work was supported by the Workplace Safety and Insurance Board of Ontario under Grant \#09036; Natural Sciences and Engineering Research Council of Canada Discovery Grant under Grant \#341664; Natural Sciences and Engineering Research Council of Canada Industrial Postgraduate Scholarship; and BlackBerry Limited. 


\section{Abstract}

This paper presents the development of a tool that allows an organization to assess its level of human factors (HF) and ergonomics integration and maturity within the organization. The Human Factors Integration Toolset (available at: TBD) has been developed and validated through a series of workshops with 45 participants from industry and academia and through industry partnered field-testing. HF maturity is assessed across five levels in 16 organizational functions based on any of 31 discrete elements contributing to HF. Summing element scores in a function determines a percent of ideal HF for the function. Industry stakeholders engaged in field-testing found the tool helped to establish the status of HF in the organization, plan projects to further develop HF capabilities, and initiate discussions on HF for performance and well-being. Improvement suggestions included adding an IT function, refining the language for non-HF specialists, including knowledge work, and creating a digital version to improve usability.

\section{Practitioner Summary}

A tool scoring HF capability in 16 organization functions has been developed collaboratively. Industry stakeholders expressed a need for the tool and provided validation of tool design decisions. Fieldtesting improved tool usability and showed that, beyond scoring HF capability, the tool created opportunities for discussions of HF-related improvement possibilities.

Keywords:

Macroergonomics, ergonomics strategy, organizational design and management, process management, operations management 


\section{1) Introduction}

Products, processes and work systems using human factors (HF) in their designs have demonstrated benefits in worker health, worker productivity and output quality (for example: Neumann and Dul 2010; Bosch et al. 2011; Falck, Örtengren, and Högberg 2010; National Research Council 2001; Widanarko et al. 2014). The societal costs associated with poor HF in the workplace are significant (Leigh 2011; Tompa, Culyer, and Dolinschi 2008). Direct health costs to the firm, though significant, are substantially less than the indirect costs (Rose, Orrenius, and Neumann 2013; de Looze et al. 2010). Financial benefits from HF related interventions have been demonstrated (Yeow and Sen 2003; Helander and Burri 1995; de Looze et al. 2010), with design-stage intervention being more cost effective and more easily completed compared to retrofitting efforts (Miles and Swift 1998). Even with the evidence of system benefits and lower investment cost in early application, $\mathrm{HF}$ is more frequently relegated to the Occupational, "Health \& Safety sidecar", considered relevant only for human resources and injury prevention, disconnected from an organization's strategy considerations and acted on reactively (Neumann and Dul 2010; Jensen 2002; Theberge and Neumann 2013). This evidence leads to the impression that the broad connection of HF to whole organizations is not well enough understood by stakeholders of varying backgrounds and disciplines.

The lack of HF consideration can stem from a number of factors. These include a lack of organizational support and the perception that $\mathrm{HF}$ is common sense, relevant only to office setups, is solely a health and safety issue, and that errors are a function of the person not the design (Helander 1999; Neumann and Dul 2010; Perrow 1983). The communication of HF information to stakeholders has also been shown to lack appropriate context in reporting information and training content to non-specialists (Village, Greig, Zolfaghari, et al. 2014; Village et al. 2013; Wulff, Westgaard, and Rasmussen 1999b; HallAndersen and Broberg 2014). Similarly, typical HF outcome measurements, providing much information on health risk and demands imposed at the worker level, do not connect well to global organization goals and metrics which tend to have more financial or customer oriented focus. Improving managers' understanding of the relation of HF to organizational goals could be made by adapting common organization tools and practices to include HF information and concepts (e.g. Village, Greig, Zolfaghari, et al. 2014). Currently, few performance measurement systems account specifically for HF, or for HF contributions beyond employee engagement and injury tracking. Methods for assessing and reporting the status of the application of HF throughout an organization are needed if $\mathrm{HF}$ is to become an effectively managed contributor to organizational goals (Neumann et al. 2013; Neumann and Village 2012). Without such a tool managers are stuck, as illustrated by the adage "you can't manage what you can't measure".

Performance measurement systems measure strategy implementation success and use collected information to challenge strategic assumptions (Bourne et al. 2000), as well as align and coordinate metrics (Melnyk et al. 2005). In part, performance measurement systems help to provide organizational direction and create change as required. Within components of the organization, audits of organization sub units, for example ISO audits for quality and environmental standards, can guide future processes and ensure standards are met. Similarly, macroergonomics, the study and design of work systems with a focus on the interaction of the organization and system, can assist with organizational change because of its systems approach to HF (Kleiner 2006; Wilson 2014). The sociotechnical framework of macroergonomics means that performance is multidimensional with many criteria and measurements 
throughout the work system (Kleiner 1996; Kleiner 2004). Missing from these frameworks and guides for implementing macroergonomics are tools that help managers quantify the state of HF capability and degree of integration within the whole organization.

Consultants reviewing organizations for HF capability are using approaches that are typically focused on injury prevention within the health and safety domain. Less common are assessments of HF integration in other organizational domains such as the production system (Bierwirth, Bruder, and Schaub 2010). The limited HF focus on well-being reinforces HF as only a health benefit, resulting in HF contributions being underexploited (Dul et al. 2012; Helander 1999; Neumann and Dul 2010; Hägg 2003; Theberge and Neumann 2013). HF has been identified as being able to provide more than a health benefit by having a systems approach, being design-driven, and focusing on both performance and well-being (Dul et al. 2012). A method of assessing and documenting the HF state in an organization, as they relate to this broad scope, is not currently available. An approach that captures the state of HF application in the whole organization is therefore needed to support efforts to apply HF more strategically.

The aim of this paper is to present the development and preliminary evaluation of a tool that can 1) establish an "ideal" reference point for what an optimal integration of HF across the organization might look like and 2) provide a means to quantitatively assess the state of HF capability and integration in a given organization with respect to the stated ideal. This will be addressed in three sections, which include theoretical development, workshop validation, and field-testing of the approach to assessing $\mathrm{HF}$ integration and capability in an organization.

\section{2) Methods}

An action research approach (Neumann, Dixon, and Ekman 2012) was used to facilitate the participatory design of the tool. With this approach an ongoing exchange spanning just over two years occurred between the research team and an industry partner to develop and test the tool. The interaction was part of a larger research project investigating the integration of $\mathrm{HF}$ in the design of production systems (Village, Greig, Salustri, et al. 2014). Experience within the university research group included approximately 150 combined years of research and practice in fields such as ergonomics, biomechanics, engineering design, sociology, industrial engineering, and health and safety. The industry partner was an international electronics design and manufacturing company. Industry contributors $(n=8)$ were part of the product realization business unit of the company. Engineers, managers, directors, and $\mathrm{HF}$ specialists within the company provided ongoing input and feedback on the tool concept, early content and layout, and executed field-testing.

\section{1) Conceptual development}

The tool development approach combines concepts from audits and performance measurement and management systems. Assessment in the tool differs from a traditional audit and assessment (e.g., ISO, European Foundation for Quality Management [EFQM]), or ergonomic self-auditing process as suggested by Bierwirth, Bruder, and Schaub (2010), in that it is not an assessment of prescribed processes or specific practices. This was an intentional choice to allow flexibility to apply the tool in different organizations. The assessment approach of this tool is similar to that of audits that can be selfadministered and obtain information from stakeholder discussions. The scope of the tool covers HF in its broadest definition as outlined by Dul et al. (2012) and defined by the International Ergonomics Association (2014). The tool is intended to cover all parts of the organization due to (1) HF being a 
systems approach, (2) the suggestion by Wilson (1994) that ergonomics should spread throughout an organization, and (3) the incorporation of HF throughout an organization can have system-wide benefits (Dul and Neumann 2009; Rose, Orrenius, and Neumann 2013; Goggins, Spielholz, and Nothstein 2008).

The tool is therefore guided by the following principles:

1) HF is a means for designing safe and effective work systems, not a goal or outcome in itself.

2) HF applies to all aspects of an organization.

3) The tool should not be prescriptive, allowing for different approaches to applying HF in different contexts.

4) Scoring should be a range from "nil" to "ideal" on a simple 0-4 scale.

5) The tool should be a self-administered organizational level assessment that can be completed via interviews with key informants.

Developing a tool based on these principles required the division of a generic organization into distinct analytical units - referred to as functions in an organization. A function is defined as a role that exists in the organization, for example the role of health and safety, or product design. The term function was chosen over department to avoid excluding small organizations where distinct departments might not exist. In such cases a single person may have responsibility for a number of functions in their organization. In this way the tool is independent of organizational divisions.

An HF element is considered to be processes, including outcome evaluations, which contribute to the achievement of the ideal HF for the function. It could be something measured, reported, a method installed, or a mindset within an organization to achieve that ideal state. Each HF element presents a single item to be evaluated for a particular organizational function.

Based on the preceding principles and definitions the framework in Figure 1 was used to guide the tool development. In this framework, the organization was broken into core functions. Within each function there exists a range of HF elements that can contribute to the ideal HF. The HF elements would then be scored for the level of maturity, reflecting for example HF integration depending on the element, based on a guiding rubric. Summing the scores for all HF elements generates a score for the function. The scores from all functions can then be reviewed to gain an appreciation of the HF capability and level of integration in the organization.

\section{PLACE FIGURE 1 ABOUT HERE}

A consensus building approach informed decisions on content in the first draft of the tool. This included a series of review meetings and workshops where modifications were made as required based on feedback to ensure stakeholder needs were met. The research team identified, using a consensus approach, the key organizational functions where HF would be relevant in an organization. The boundaries of each organizational function was then defined. Function definitions were necessary to focus the scope in the remaining development steps and to align future tool users with the context with which the function was considered. The ideal HF for each function was then defined by the team based on a number of key themes or requirements for exemplary $\mathrm{HF}$, as supported by the literature (highlighted below), and concepts found in existing HF program assessments, for example in the 
participating organization. The next step was to establish a set of key HF elements contributing to the $\mathrm{HF}$ ideal for each function. This was based on satisfying the components of the definition within the function ideal, the literature (highlighted below), and existing HF program assessment concepts. For each $\mathrm{HF}$ element within a given function, a statement reflecting the ideal $\mathrm{HF}$ was created for that $\mathrm{HF}$ element as it related to the function. This was considered reflective of mature, 'ideal', HF integration for a given function.

The development of the definitions of the HF ideal for each function and the creation and definition of the HF elements supporting the functions was guided by a number of inter-related themes in the scientific literature that formed a basic grounding for the creation of the tool. Key themes included:

- HF has been suggested to take a systems approach, be design driven, and combine performance and well-being (Dul et al. 2012; Dul and Neumann 2009; Neumann and Dul 2010; Wilson 2014; Chapanis 1995).

- The impact of HF needs to be measured and reported in a manner that is understood by stakeholders, and relates to company key performance indicators, strategy, and business goals to better manage HF, improve its utilization, and support stakeholder and organizational success (Rodrigues 1999; Dul et al. 2012; Dul and Neumann 2009; Fulton Suri 2001; So and Lam 2014; Edwards and Jensen 2014; Village et al. 2015).

- HF measures need to address direct and indirect costs, return on investment, cost-benefit analysis, and compensation claims so that $\mathrm{HF}$ is viewed as an organization investment and not a cost (Hägg 2003; Rose, Orrenius, and Neumann 2013; Goggins, Spielholz, and Nothstein 2008; Wilson 1994).

- The application of HF should be throughout an organization, from strategy development to product development and associated processes (Dul and Neumann 2009; Chapanis 1995; Stanton and Stammers 2008; Perrow 1983).

- The HF implementation, HF integration, and the HF program should be evaluated regularly (Bierwirth, Bruder, and Schaub 2010; Kragt 1995).

- Some initiatives need to have an integrated HF specialist but should always employ a participative approach and involve everyone (Wulff, Westgaard, and Rasmussen 1999a, 1999b; Vink, Koningsveld, and Molenbroek 2006; Wilson 1994; Kragt 1995).

- Reviewing HF components of a product or process should consider not only the physical aspects but the psychosocial and cognitive aspects as well (Hägg 2003; Fulton Suri 2001; Wilson 2014).

- User-centered approaches should be used and include an empathetic view of the people involved during design, review, and implementation (Fulton Suri 2001; Eason 1995).

- Ensuring high quality HF is further dependent on continual HF training and learning, and providing guidelines of relevant context for non-specialists (Hall-Andersen and Broberg 2014; Chapanis 1995; Dul et al. 2012).

This non-exhaustive list was supplemented by the research team's experience and view-points on the potentially ideal situation for HF in organizations, reviewed audits used by consultants or within organizations, the ongoing reviews and discussions with the industry partner and the feedback and commentary obtained from subject matter experts in the review workshops (see section 2.2). These 
interactions provided ongoing face validity and content validity checks from the perspectives of the participating managers, engineers, and ergonomics specialists.

To create a scoring range within the tool, the ideal HF element was scaled across four other levels of maturity, each level having its own descriptive statement. This continuum, bookended by statements for the best and worst case scenarios, was conceptually similar to the levels of the Baldridge Performance Excellence Program (National Institute of Standards and Technology 2012) which is widely used in industry today. The five levels also allowed for the use of the terms none, rarely, occasionally, frequently, and always as verbal descriptors to more easily differentiate between the different levels. Scores, assigned to each level to reflect a "nil" to "ideal" scenario, ranged from 0 to 4 , with 4 representing the ideal scenario. A score for a function was obtained by summing all individual element scores and dividing it by the total score possible. This scoring approach was familiar to, and acceptable for, the participating industry personnel.

\section{2) Tool review workshop}

Three workshops were held to review tool content (i.e., that the tool contains appropriate and necessary information) and face validity (i.e., that the tool does what it appears to) (Trochim and Donnelly 2007; DeVon et al. 2007). A convenience sample of participants (8-20 participants per workshop, 45 total participants) were recruited from professional societies and graduate programs of the fields of ergonomics, industrial hygiene, health and safety, and industrial engineering. One workshop recruited ergonomists from the Association of Canadian Ergonomists, another workshop recruited industrial engineers from the local chapter of the Institute of Industrial \& Systems Engineers, while the third workshop was completed in a graduate ergonomics course that included industrial hygienists with a range of professional experience. Workshops were structured to guide the participants through the tool development process and the background of the tool. Four different functions were reviewed in depth per workshop. Breakout groups allowed the participants to simultaneously review and develop their own sections of the tool for comparison with, and to provide comments with respect to face validity and content validity of, the current tool. Participants were asked to provide comments and feedback at the end of the workshop using a seven point Likert-type scale. A one-sample t-test with $95 \%$ confidence interval tested the null hypothesis of an opinion neutral midpoint on each of the five following statements about the need for the tool and the appropriateness of content and tool design:

1. The HFIT is a tool that is needed.

2. The functions chosen in an organization are appropriate for the HFIT's scope.

3. The element themes are appropriate and significantly cover human factors and ergonomics concerns.

4. The definition of World Class, or ideal HF are appropriate and accurate for the tool.

5. The reporting format is user friendly and easy to understand.

The presentation of information and general discussion questions were audio recorded for postworkshop verification of any key comments. Participants were also asked to write down information and ideas from brainstorming during small group work. This information was collected for review after 
the workshop. All comments and information obtained were reviewed and used to improve the tool further.

\section{3) Field-testing of the tool}

HF specialists in the partner company were recruited to use the tool to assess the level to which the organization considers human factors in its activities. The tool was presented to the HF specialists, and a high-level explanation given as to how it was to be used. Participating HF specialists recruited subject matter experts, usually one or two managers with responsibility for the function in question, they deemed appropriate for assessing the given function in their organization. The HF specialists worked with the subject matter expert(s) to score each HF element for the given function by either interviewing the subject matter expert(s) to gather information or by facilitating the use of the tool by the subject matter expert(s). Specialists noted any comments about the usability and content of the tool. HF specialists were left on their own during the use of the tool, though researcher assistance was available when requested by participants. During a number of assessments, the researcher observed the HF specialists using the tool and recorded comments about tool usability and content. After each scoring, and, again when all function assessments were completed, the researcher and HF specialist(s) met for a semi-structured interview on key development and experience themes about the tool. The discussion was guided by questions on the user experience, the appropriateness and scoring of content, gaps in information, and application of the tool and use of the outcome information. With permission, discussions were recorded to verify accuracy of comments. The interview data was supplemented with ongoing recorded discussions, field notes and written feedback on the user's experience with the tool. Field notes and transcription of key comments from all interactions involving discussion of the tool were reviewed for relevant emergent themes using an inductive analysis approach (Thomas 2006). Analysis focussed specifically on reactions to the tool, issues of its application, and design improvement suggestions that were then used to help improve the tool further throughout the project.

\section{3) Results}

This section describes the final version of the tool that emerged from the interactive approach described above. Readers interested in viewing the entire tool may access it freely at [WEB ADDRESS TBD].

\section{1) Conceptual development results}

The complete, initial tool was a document that included definitions of all functions and HF elements to provide context for the user, scoring sheets for each HF element in a function, and summary scoring tables for an individual function and all functions combined. The tool has been called the Human Factors Integration Toolset, consisting of an assessment tool for each function. An example summary scoring checklist and associated questions for scoring for the Training function can be found in the Appendix.

\subsection{1) Organizational functions}

Research group discussion generated a list of 16 functions in the test version of the tool. These included:

1. Environmental, Health \& Safety

3. Training

5. Tooling
2. Construction and Fabrication

4. Operations/Supervision

6. Product/Service Design 
7. Medical Services \& Claims Management

9. Marketing/External

Communications/Advertising/ Retail/Sales

11. Finance

13. Maintenance

15. Human Resource Management (Hiring

and Retention, Employee and Labour

Relations and Internal Communications)
8. System Engineering / Design

10. Logistics (Shipping/Receiving/Material

Handling/Warehousing/Storage)

12. Scheduling/Operations Planning

14. Quality

16. Organizational Strategy Development

(Board of Directors/Senior Management)

All functions are defined for the role in the organization, the HF relation, and the HF ideal. This information provides the context behind the development of the function in order for tool users to find the best fit to their situation. Two examples of definitions of the ideal HF for a function are shown below for the functions Training and System Engineering / Design as used during the testing phase (minor revisions were made for the posted version based on this research).

\section{Training:}

Training modules are reviewed and compliant with promoting effective HF practices (well-being and performance). HF awareness module is used and employee introduction training is completed with frequent refresher. HF information in training has both general, but simple HF information component, and a component that is context specific to the organization. Role specific training provided to front line employees, managers and system designers.

\section{System Engineering / Design:}

$H F$ inclusion as a key contributor with the equivalent power to stop a process and force revisions to the design. All modifications are automatically considered for HF impact and interaction without prompting. Lessons learned from other experiences feed into any new design. All HF concerns addressed while in the digital/development stage. Layout allows flexibility to cover entire working population.

\subsection{2 "Elements" to be evaluated}

A list of 31 discrete HF element statements were created and structured to improve the number of commonly labelled terms between the functions (see Figure 2). An average of 10.2 functions were served by a single HF element statement $(\min =2, \max =16)$. The average number of elements per function was 19.7 ( $\min =12, \max =26$ ). In principle each functions' assessment tool from the HFIT can be used independently to determine the relationship to the proposed ideal HF for that function.

\section{INSERT FIGURE 2 ABOUT HERE}


Examples of three elements and their HF ideal, as used during the evaluations, are shown below:

HF Guidelines:

Refers to standards and recommendations for procedures and outcomes. Guidelines are industry based or established by a subject matter expert. They are reviewed frequently for relevance and tailored to an individual organization to increase understanding.

\section{Lessons learned are logged and acted upon:}

$H F$ related lessons (e.g. from projects or improvements) are logged and circulated among key people to support continuous improvement. The information exist as a living document space that is updated regularly and provides continual feedback to the next lifecycle of service or product.

\section{Celebrated - project promotion and ideal:}

Successful HF specific projects are celebrated within the company and promoted. Ideas brought forth by employees are noted and published. The culture of HF and desire to be a World Class HF leader is evident in the organization.

An example of the rubric created from the HF ideal for HF Guidelines is shown in Table 1 for the Training function. Users would choose the statement that best applies to their situation to determine the appropriate score. Rubrics used for all the HF elements of the Training function can be found in the Appendix. Only relevant elements were included in the tool for each function as illustrated in Figure 2. Wording in the elements was adjusted slightly to align with the particular function (e.g. to include the function's name).

\section{INSERT TABLE 1 ABOUT HERE}

\section{2) Tool review workshop results}

Workshop attendees included subject matter experts from local chapters of ergonomics and industrial engineering associations, and graduate students. Participants had backgrounds from manufacturing, consulting, government, health care, meat processing, oil and gas, and process improvement, among others. Comments on the tool were, at times, unique to individual workshop group specialities, but, at other times, did reflect a commonality across all subject matter experts. Participants on average rated the need for the tool (see \#1 in Figure 3 ) at 5.7 on the 7 point scale $(n=45, t(44)=10.993, p<0.001)$. Associated positive comments included 'I think this is a revolutionary tool and I haven't seen anything like this', that 'this is quantifying something not previously quantified', and that 'it's needed so long as there are enough personnel that are capable/knowledgeable about HF to use it'. Some were 'unsure if companies are ready...', that the tool 'seems to be useful to more advanced companies (overall scope)' and could 'see it(s) use but wonder how effective it would be on a wide scale'.

\section{INSERT FIGURE 3 ABOUT HERE}


Participants suggested that research and development and information technology were two functions to also include. Regardless, workshop participants agreed (5.6 out of $7, n=43, t(42)=12.221, p<0.001$ ) the functions were appropriate for the HFIT's scope (see \#2 in Figure 3). Some participants thought some functions already included could be expanded on, be 'more industry specific' and 'include some other health care functions'. Others thought that the functions 'seem to make sense' and that the 'functions will become better defined with more exposure in industry'. Comments on HF elements were also positive, though an assessment by participants was difficult to make in the workshop due to the volume of material and the associated time to complete reviews. One workshop participant did suggest that they 'would like to see more behavioural aspects of human factors' and another stated that they would need to 'ensure that (the) user understands human factors applications to ensure accuracy of reporting/rating'. The idea of 'World Class, or ideal HF' (see \#4 in Figure 3) was the most agreed with feedback statement $(5.9$ out of $7, n=43, t(42)=11.765, p<0.001)$ but left one participant to wonder if we can'...ever really achieve World Class', and another to state that '...because no standards exist for application of HF it's hard to define World Class'; however the participant followed that statement by adding that World Class, or ideal HF 'is defined well for the tool though'. The least agreed with feedback statement (\#5 in Figure 3 ) regarded the reporting format (5.0 out of $7, n=42, t(41)=5.270, p<0.001$ ).

Five themes emerged from the workshop comments. These included information clarity, tool length and volume of information, differentiation of information, and use of an electronic format. Some suggested the reporting clarity was concise and clear while others stated it could be confusing and needed explanations and specific examples. Others commented that the terminology and content of the paper based tool was 'geared towards educated individuals' and 'not friendly at all' and more easily understood by ergonomic or HF specialists. Similarly, some participants commented on the need for more clear section divisions and that some users may have 'trouble differentiating the different score categories'. The volume of information was considered daunting and long and that future versions of the tool should consider an electronic format.

\section{3) Field-testing results}

Eleven documented dedicated meetings and eight informal conversations within other meetings were held on the HFIT in the partner company. These engaged a broad range of relevant stakeholders including HF specialists, engineers, and engineering managers. The meetings ranged in their length and in the depth to which they discussed specific areas of the HFIT. Five functions, with six total subject matter expert participants, were able to be tested in the field (Environmental, Health \& Safety, Medical Services \& Claims Management, Product/Service Design, Marketing/External Communications/Advertising/Retail/Sales, and Human Resource Management) with researcher participation in three of the sessions. Attempts made to test other functions were unsuccessful due to resource and personnel constraints in the company. Comments from the interactions are clustered into three key themes representing the need for the tool, the reaction to the HFIT, and the application and benefits of the tool.

\subsection{1) The need to measure HF across an organization:}

The need for a method to assess ergonomics in an organization was evident from industry partner comments. After an exercise within the larger research project of rating the organization's HF level of integration, one engineer commented 'I would like to get to 10 and I don't know what 10 looks like and 
that is why we need your help'. An engineering director commented in a separate meeting on the desire to be able to show how the impact of multiple human factors projects could be demonstrated to their leadership team - '[We] can demonstrate why we're doing things.... We can say this is why we're choosing this project. There [are] benefits for it but we also have to grow in this area. This is an area we are weak in'.

\subsection{2) The reaction to the HFIT:}

The introduction of the tool to the HF group was positive, and appeared to fill a need and be appropriate in scope. One HF specialist stated 'I would love to see this applied...across our entire organization...it's just going to keep moving, in terms of overall, the evolution of ergonomics'. Another $\mathrm{HF}$ specialist believed 'any tool where [you] can ask pertinent questions to introduce [people] to ergonomics is good.... find the information is fine..... think it's general enough where the person using it can make some adjustments for the work that's being done in your place'. Similarly, an engineering director was also supportive '...I like it. I think the grades are good... [it] is a great evaluation tool for me'.

An HF specialist highlighted the challenge with applying the HFIT in other industries where there is 'still heavy injury focus with most people', though they thought that in large manufacturing (e.g. automotive assembly) HF is seen differently so the tool may be adopted there sooner. The HF specialist believed that the tool would not be adopted and used by just anyone, especially if they did not see the value 'in human factors as a whole' and make the connection to their work 'if it wasn't related to anything that helped them make their job easier or quantify stuff or improve, whatever their service or product was'. They believed this was in part due to the complexity of HF, people's general knowledge of HF, and not completely a fault of the tool. Even for those with some familiarity of ergonomics they might not understand the connection with human factors. Two HF specialists commented that even the term ergonomics would be more well-known than human factors in their organization with one of them stating that there would be a need to 'be sure that people have a good foundation of understanding of what human factors is and what this [tool] is designed to accomplish to make sure that they receive the results..... can see the context might be misinterpreted'. As a result, one HF specialist believed that in its current form the tool is best used by ergonomists, in part because '...I have difficulty [explaining] ergonomics to people other than injury prevention.... think most people understand the physicality of work.....looking at it from a productivity standpoint they don't....grasp that because I don't think in their mind they are able to measure that kind of thing'. The tool was also highlighted to have benefits beyond the case organization as a tool for consultants proposing work, shown when one HF specialist commented '... as a consultant it would be an extremely beneficial tool. To be able to go in and say "Look. As part of our services we will do a survey...an audit up front and when we're done you should have X\% improvement" '. While some saw the novelty of the tool creating challenges for uptake in a conventional health-focussed practice of ergonomics, most participants saw the tool needed and as creating the potential to open new doors for applying ergonomics more broadly in organizations.

\subsection{3) Application and benefits of the tool}

Different stakeholders envisioned different applications of the tool. One engineering director thought its application could be similar to lean assessments, where effectiveness is evaluated across industries and organizations. HF specialists saw application in understanding the current state of HF in the organization, developing conversations around $\mathrm{HF}$, and planning projects to further develop the level of $\mathrm{HF}$ integration in the organization. When establishing the current state of HF, one specialist thought the 
tool could help to change the culture of HF beyond focussing solely on wellbeing 'to talk about human performance and efficiency' as the company transitioned to a more lean workforce. This specialist had found it 'hard for me to push [the performance agenda] up the line' but that 'ultimately if we can show the company that integrating human factors and getting everybody to four, that's where you're going to have your most success in eliminating the conditions that would prevent people from performing'. In this way it was possible to use the tool to develop conversations with groups in the organization who the HF specialists were 'not sure how much they see the relation [to HF]'. The view of an HF specialist was that they were 'for the most part...on the outside looking in' but with the tool they now have a 'means to quantify where that is for us', giving other stakeholders 'some incentive' to change, as well as provide a means for the HF group of selling their services.

Regardless of the score from the tool, the HF group perceived there was good output. One HF specialist illustrated the benefit when they commented 'We would benefit from this in some way whether it's the actual score, [or] whether it's ...having those discussions'. With experience, the one HF specialist 'started to figure out how to use [the tool]'. They recognized that 'each one of these [spreadsheet] tabs...in themselves...is a project' and began to plan projects to improve the HF capability as they started to realize 'there were deficiencies and/or good things coming out of the tool and understanding that this is where we want to go from an ergonomics program perspective that helped shape it into a project'. Building on this perspective they commented how the results inspire projects that are guided by the information within the levels of maturity of the HF elements and enable discussions to move HF forward; 'I feel like the questions itself are enough to say "Okay. You're at this level. You know you want to go to this level. Here are some metrics to show you the difference and these are the things that we're going to do to get you there"... as opposed to now where we don't even know where that is and how to get to the next point'. In this case, the tool would also help to assess and audit their change progress through the levels of maturity. The scores and the statements on HF maturity could also help to provide a guide to change and a method to quantify that change. This organizational level assessment had been previously unavailable to the participants.

\section{4) Discussion}

The Human Factors Integration Toolset (HFIT) has been developed to allow users to better understand the HF-related capabilities existing in their organization and the level of integration and maturity of these capabilities relative to a defined ideal. The tool does not specifically prescribe what should be done in an organization, such as an 'audit' tool which prescribes specific procedures. Instead it provides guiding HF elements as defined by subject matter experts using a consensus-based approach. These guiding principles are expected to benefit employee wellbeing and organizational performance per the position paper on the future of ergonomics (Dul et al. 2012). This principled approach, and the use of functions instead of departments, is intended to allow the flexibility to apply the tool in organizations of different sizes. The modular design of the tool, and its implementation in spreadsheet software, make it amenable to further development and customization to meet specific user needs. Future research should examine how the tool can be adapted beyond the manufacturing context in which it was developed, for example healthcare systems might require new functions and elements. While conventional 'micro' ergonomics tools provide information on individual risk factors in the workplace (for examples see Takala et al. 2010), the HFIT provides a more 'macro' assessment of how HF is applied across the organization. 
Although the comprehensiveness of the HFIT makes for a large document, which was of some concern to stakeholders, the review time of 30-60 minutes per function and total estimated review time of 8-16 hours is comparable to occupational health and safety management audits reviewed by Robson et al. (2012). Total resources needed to collect the data depends on the approach chosen to scoring. User feedback suggested an HF specialist or ergonomist would likely be best suited to collect the data or facilitate the use of the tool, possibly in dialog with the subject matter expert(s). Data can be collected individually or through group consensus. In group data collection settings, tool users' reports of how the assessment process initiated new conversations about how HF could be used in the organization were consistent with the experiences of Village, Greig, Zolfaghari, et al. (2014) using new HF design tools. Similarly, organizational level tools like the Balanced Scorecard have been associated with new discussions in relation to health care system improvements (Kollberg and Elg 2011). This tool also seems to be acting as a "boundary spanning" object supporting communication regarding the application of ergonomics across organizational boundaries (Garrety and Badham 1999; Broberg, Andersen, and Seim 2011) by its ability to facilitate dialogues with people less familiar with HF. These conversations can help to demonstrate that HF extends beyond health and safety and connects to the performance of the whole organization as a means of gaining buy-in from stakeholders. The tool could support the macroergonomics approach as described by Kleiner (2004), the integration of HF as identified by Dul and Neumann (2009), and the development of the HF discipline (Dul et al. 2012; Norros 2014). The conversations within the organization can also help HF specialists to better appreciate how their knowledge is, and can be, integrated in other domains in the organization, such as Village, Salustri, and Neumann (2013) and Village, Salustri, and Neumann (2016) found with the use of cognitive mapping. These new understandings can help organizations find new ways to apply HF throughout their systems and contributes to the "organizational work" that many ergonomists are engaged in (Theberge and Neumann 2010).

The associated challenge to increase the HF score creates a target for the organization. The use of goal setting has been shown to affect performance across a range of environments with the setting of specific goals potentially providing improved performance (Latham and Yukl 1975; Latham and Locke 2007; Doran 1981). Hierarchically arranging goals, as the maturity levels within the HF elements and the HF elements themselves create for the function, creates short-term feedback on progress while simultaneously extending the user's vision to the future (Zimmerman 2008). Longitudinal case studies and action research methodologies could help understand this process of the uptake of HF in more detail and could become crucial in understanding long term success of macroergonomic interventions (Neumann, Dixon, and Ekman 2012).

Validity is a challenge with such a tool, since there is no existing measure of the construct of HF maturity in an organization. Indeed the construct itself is multi-faceted and ephemeral. We see this tool as a start point in this important area with much research remaining to be done. This project used both consensus and participatory development approaches, with ongoing interaction events, to help enhance face and content validities. This approach also helped to ensure the tool would meet the needs of target user groups - which the evaluation helped confirm. The consensus approach was used when creating the functions, HF elements, and defining the ideal. This is similar to the approach of using a panel of subject matter experts in the development of standards, performance management systems, and organizational assessments (International Organization for Standardization 2013; Kaplan and Norton 1996; European Foundation for Quality Management 2015). Participants in the workshops and field- 
testing helped improve the tool including language clarity, managing the volume of information, and improving ease of data entry. In general, user comments were consistent with tool criteria identified in previous research including time to use, training, difficulty to use, and usefulness (Perez and Neumann 2015).

The current tool scoring is based on a simple addition across all functions. While this poses a logical start-point, there may be merit in considering a weighted or non-linear approach to improve predictive validity and potentially better differentiate and reflect the relative contributions of a given HF element to predicting overall performance. Further testing of the predictive validity of the tool (Trochim and Donnelly 2007), with respect to short and long term human outcomes and organizational performance outcomes, remains a task for future research. Larger datasets could be used to identify better element and function weightings to generate more predictive scoring algorithms. Testing of content validity was limited by time constraints in the workshops, the tool was too large to completely test in each workshop, and testing was at the discretion of personnel in the field test, who were limited by organizational and resource constraints. A more structured testing of the construct validity with respect to the HF elements is also warranted. While all functions were reviewed in meetings, two functions, Organizational Strategy Development and Scheduling/Operations Planning, received neither workshop or field-test review. A challenge of testing these functions is that they are outside the traditional focus of ergonomists, who tend to be affiliated with OHS and HR functions (Theberge and Neumann 2013). Previous theoretical discussion has linked ergonomics broadly to corporate strategies (Dul \& Neumann, 2009) and, in our view, justifies keeping the broad range of functions as suggested here. Further testing of these functions, and possible expansion, remain an ongoing research issue.

\section{5) Conclusion}

This paper has presented the development and preliminary testing of a novel tool to assess the human factors (HF) capability and integration across an organization, a macroergonomic tool that has not been available previously. The creation of the Human Factors Integration Toolset allows the user to score the integration and capability of HF in a number of supporting HF elements across five levels of maturity for, currently, up to 16 functions within an organization. Consensus-based development combined research and industry experience to develop and field test the tool while subject matter expert workshops contributed to face and content validity testing. Qualitative and quantitative evaluation revealed participants' agreement for the need for this type of assessment tool and an appreciation of the tool itself. Scoring HF maturity in the partner organization's functions allowed HF specialists to better appreciate the level of understanding of $\mathrm{HF}$ in the organization as well as the effectiveness of $\mathrm{HF}$ programs. The ability of the tool to develop meaningful discussions with other stakeholders about the role and contribution of HF to their function was a highlighted benefit of the use of the tool. Specialists saw the tool as supporting HF-related development projects that could be guided, with progress scored, by the tool. The tool is ready for broader validity testing across different organizations and is freely available on the internet (web address TBD). 


\section{References}

Bierwirth, M., R. Bruder, and K. Schaub. 2010. "Total Ergonomics Management." In Advances in Human Factors, Ergonomics, and Safety in Manufacturing and Service Industries, 108-18. CRC Press.

Bosch, T., S. E. Mathiassen, B. Visser, M. P. de Looze, and J. H. van Dieen. 2011. "The effect of work pace on workload, motor variability and fatigue during simulated light assembly work." Ergonomics 54 (2):154-68. doi: 10.1080/00140139.2010.538723.

Bourne, M., J. Mills, M. Wilcox, A. Neely, and K. Platts. 2000. "Designing, implementing and updating performance measurement systems." International Journal of Operations \& Production Management 20 (7):754-71.

Broberg, O., V. Andersen, and R. Seim. 2011. "Participatory ergonomics in design processes: the role of boundary objects." Applied Ergonomics 42 (3):464-72. doi: 10.1016/j.apergo.2010.09.006.

Chapanis, A. 1995. "Ergonomics in product development: a personal view." Ergonomics 38 (8):1625-38.

de Looze, M. P., P. Vink, E. A. P. Koningsveld, L. Kuijt-Evers, and J. W. Van Rhijn. 2010. "Costeffectiveness of ergonomic interventions in production." Human Factors and Ergonomics in Manufacturing \& Service Industries 20 (4):316-23. doi: 10.1002/hfm.20223.

DeVon, H. A., M. E. Block, P. Moyle-Wright, D. M. Ernst, S. J. Hayden, D. J. Lazzara, S. M. Savoy, and E. Kostas-Polston. 2007. "A psychometrick toolbox for testing validity and reliability." Journal of Nursing Scholarship 39 (2):155-64.

Doran, G. T. 1981. "There's a S.M.A.R.T. way to write management's goals and objectives." Management Review 70 (11):35-6.

Dul, J., R. Bruder, P. Buckle, P. Carayon, P. Falzon, W. S. Marras, J. R. Wilson, and B. van der Doelen. 2012. "A strategy for human factors/ergonomics: developing the discipline and profession." Ergonomics 55 (4):377-95. doi: 10.1080/00140139.2012.661087.

Dul, J., and W. P. Neumann. 2009. "Ergonomics contributions to company strategies." Applied Ergonomics 40 (4):745-52. doi: 10.1016/j.apergo.2008.07.001.

Eason, K. D. 1995. "User-centred design: for users or by users?" Ergonomics 38 (8):1667-73.

Edwards, K., and P. L. Jensen. 2014. "Design of systems for productivity and well being." Applied Ergonomics 45 (1):26-32. doi: http://dx.doi.org/10.1016/j.apergo.2013.03.022.

European Foundation for Quality Management. 2015. "Our history." Accessed July 28, 2015. http://www.efqm.org/about-us/our-history.

Falck, A.-C., R. Örtengren, and D. Högberg. 2010. "The impact of poor assembly ergonomics on product quality: A cost-benefit analysis in car manufacturing." Human Factors and Ergonomics in Manufacturing \& Service Industries 20 (1):24-41. doi: 10.1002/hfm.20172.

Fulton Suri, J. 2001. "The Ergonomics Society--the Society Lectures 1999: the next 50 years: future challenges and opportunities for empathy in our science." Ergonomics 44 (14):1278-89. doi: 10.1080/00140130110105850.

Garrety, K., and R. Badham. 1999. "Trajectories, social worlds, and boundary objects: A framework for analyzing the politics of technology." Human Factors and Ergonomics in Manufacturing 9 (3):277-90.

Goggins, R. W., P. Spielholz, and G. L. Nothstein. 2008. "Estimating the effectiveness of ergonomics interventions through case studies: implications for predictive cost-benefit analysis." Journal of Safety Research 39 (3):339-44. doi: 10.1016/j.jsr.2007.12.006.

Hägg, G. M. 2003. "Corporate initiatives in ergonomics-an introduction." Applied Ergonomics 34 (1):315. 
Hall-Andersen, L. B., and O. Broberg. 2014. "Integrating ergonomics into engineering design: The role of objects." Applied Ergonomics 45 (3):647-54.

Helander, M. G. 1999. "Seven common reasons to not implement ergonomics." International Journal of Industrial Ergonomics 25 (1):97-101.

Helander, M. G., and G. J. Burri. 1995. "Cost effectiveness of ergonomics and quality improvements in electronics manufacturing." International Journal of Industrial Ergonomics 15:137-51.

International Ergonomics Association. 2014. "The Discipline of Ergonomics." International Ergonomics Association, Accessed October 8, 2014. http://www.iea.cc/whats/index.html.

International Organization for Standardization. 2013. "Standards Development." Accessed July 17. http://www.iso.org/iso/home/standards development.htm.

Jensen, P. L. 2002. "Human factors and ergonomics in the planning of production." International Journal of Industrial Ergonomics 29 (3):121-31.

Kaplan, R. S., and D. P. Norton. 1996. The Balanced Scorecard : Translating Strategy Into Action. Boston, Mass: Harvard Business School Press.

Kleiner, B. M. 1996. "Macroergonomics lessons learned from large scale change efforts in industry, government, and academia." In Human Factrors in Organizational Design and Management - $V$, edited by O. Brown Jr and H. W. Hendrick, 483-7. Amsterdam: North-Holland.

Kleiner, B. M. 2004. "Macroergonomics as a large work-system transformation technology." Human Factors and Ergonomics in Manufacturing 14 (2):99-115.

Kleiner, B. M. 2006. "Macroergonomics: analysis and design of work systems." Applied Ergonomics 37 (1):81-9. doi: 10.1016/j.apergo.2005.07.006.

Kollberg, B., and M. Elg. 2011. "The practice of the Balanced Scorecard in health care services." International Journal of Productivity and Performance Management 60 (5):427-45. doi: 10.1108/17410401111140374.

Kragt, H. 1995. "Enhancing industrial performance: experiences of integrating the human factor." Ergonomics 38 (8):1674-85.

Latham, G. P., and E. A. Locke. 2007. "New developments in and directions for goal-setting research." European Psychologist 12 (4):290-300.

Latham, G. P., and G. A. Yukl. 1975. "A review of research on the application of goal setting in organizations." Academy of Management Journal 18 (4):824-45.

Leigh, J. P. 2011. "Economic burden of occupational injury and illness in the United States." Millbank Quarterly 89 (4):728-72.

Melnyk, S. A., R. J. Calantone, J. Luft, D. M. Stewart, G. A. Zsidisin, J. Hanson, and L. Burns. 2005. "An empirical investigation of the metrics alignment process." International Journal of Productivity and Performance Management 54 (5/6):312-24. doi: 10.1108/17410400510604494.

Miles, B. L., and K. Swift. 1998. "Design for manufacture and assembly." Manufacturing Engineer 77 (5):221-4.

National Institute of Standards and Technology. 2013. "Baldridge Performance Excellence Program." Accessed August 4, 2013. http://www.nist.gov/baldrige/.

National Research Council. 2001. Musculoskeletal Disorders and the Workplace - Low Back and Upper Extremities. Edited by Panel On Musculoskeltal Disorders In The Workplace, National Academy of Science and Institute of Medicine (US). Washington DC: National Academy Press.

Neumann, W. P., S. M. Dixon, and M. Ekman. 2012. "Ergonomics action research I: shifting from hypothesis testing to experiential learning." Ergonomics 55 (10):1127-39. doi: 10.1080/00140139.2012.700327. 
Neumann, W. P., and J. Dul. 2010. "Human factors: spanning the gap between OM and HRM." International Journal of Operations \& Production Management 30 (9):923-50. doi: 10.1108/01443571011075056.

Neumann, W. P., M. Greig, J. Village, and R. Wells. 2013. "Indicators for managing human centred manufacturing." In The 11th International Conference on Manufacturing Research - ICMR 2013. Cranfield University, Bedfordshire, UK.

Neumann, W. P., and J. Village. 2012. "Ergonomics action research II: a framework for integrating HF into work system design." Ergonomics 55 (10):1140-56. doi: 10.1080/00140139.2012.706714.

Norros, L. 2014. "Developing human factors/ergonomics as a design discipline." Applied Ergonomics 45 (1):61-71. doi: 10.1016/j.apergo.2013.04.024.

Perez, J., and W. P. Neumann. 2015. "Ergonomists' and engineers' views on the utility of virtual human factors tools." Human Factors and Ergonomics in Manufacturing \& Service Industries 25 (3):27993.

Perrow, C. 1983. "The organizational context of human factors engineering." Administrative Science Quarterly 28 (4):521-41.

Robson, L. S., S. Macdonald, G. C. Gray, D. L. Van Eerd, and P. L. Bigelow. 2012. "A descriptive study of the OHS management auditing methods used by public sector organizations conducting audits of workplaces: Implications for audit reliability and validity." Safety Science 50 (2):181-9. doi: 10.1016/j.ssci.2011.08.006.

Rodrigues, C. C. 1999. "Ergonomic Tenets and the Bottom Line." Proceedings of the Human Factors and Ergonomics Society Annual Meeting 43 (14):820-4. doi: 10.1177/154193129904301402.

Rose, L., U. E. Orrenius, and W. P. Neumann. 2013. "Work environment and the bottom line: Survey of tools relating work environment to business results." Human Factors and Ergonomics in Manufacturing \& Service Industries 23 (5):368-81. doi: 10.1002/hfm.20324.

So, R. H., and S. T. Lam. 2014. "Factors affecting the appreciation generated through applying human factors/ergonomics (HFE) principles to systems of work." Applied Ergonomics 45 (1):99-109. doi: 10.1016/j.apergo.2013.04.019.

Stanton, N. A., and R. B. Stammers. 2008. "Bartlett and the future of ergonomics." Ergonomics 51 (1):113. doi: $10.1080 / 00140130701801116$.

Takala, E. P., I. Pehkonen, M. Forsman, G. A. Hansson, S. E. Mathiassen, W. P. Neumann, G. Sjøgaard, K. B. Veiersted, R. H. Westgaard, and J. Winkel. 2010. "Systematic evaluation of observational methods assessing biomechanical exposures at work." Scandinavian Journal of Work, Environmental \& Health 36 (1):3-24.

Theberge, N., and W. P. Neumann. 2010. "Doing 'organizational work': expanding the conception of professional practice in ergonomics." Applied Ergonomics 42 (1):76-84. doi: 10.1016/j.apergo.2010.05.002.

Theberge, N., and W. P. Neumann. 2013. "The Relative Role of Safety and Productivity in Canadian Ergonomists' Professional Practices." Relations Industrielles/Industrial Relations 68 (3):387-408.

Thomas, D. R. 2006. "A General Inductive Approach for Analyzing Qualitative Evaluation Data." American Journal of Evaluation 27 (2):237-46. doi: 10.1177/1098214005283748.

Tompa, E., A. J. Culyer, and R. Dolinschi. 2008. Economic evaluation of interventions for occupational health and safety: developing good practice. Oxford: Oxford University Press.

Trochim, W. M. K., and J. P. Donnelly. 2007. Research methods knowledge base. Mason, OH: Thomson Custom Publishing.

Village, J., M. Greig, F. Salustri, S. Zolfaghari, and W. P. Neumann. 2014. "An ergonomics action research demonstration: integrating human factors into assembly design processes." Ergonomics 57 (10):1574-89. doi: 10.1080/00140139.2014.938128. 
Village, J., M. Greig, S. Zolfaghari, F. Salustri, and W. P. Neumann. 2014. "Adapting Engineering Design Tools to Include Human Factors." IIE Transactions on Occupational Ergonomics and Human Factors 2 (1):1-14. doi: 10.1080/21577323.2014.905884.

Village, J., F. A. Salustri, and W. P. Neumann. 2013. "Cognitive mapping: Revealing the links between human factors and strategic goals in organizations." International Journal of Industrial Ergonomics 43 (4):304-13. doi: 10.1016/j.ergon.2013.05.001.

Village, J., F. A. Salustri, and W. P. Neumann. 2016. "Cognitive mapping links human factors to corporate strategies " European Journal of Industrial Engineering 10 (1):1-20.

Village, J., C. Searcy, F. Salustri, and W. Patrick Neumann. 2015. "Design for human factors (DfHF): a grounded theory for integrating human factors into production design processes." Ergonomics 58 (9):1529-46. doi: 10.1080/00140139.2015.1022232.

Village, J. L., T. Annett, M. A. Greig, and W. P. Neumann. 2013. "Ergonomics training for engineers: are we meeting their needs?" In 44th Annual Conference of the Association of Canadian Ergonomists. Whistler, Canada.

Vink, P., E. A. Koningsveld, and J. F. Molenbroek. 2006. "Positive outcomes of participatory ergonomics in terms of greater comfort and higher productivity." Applied Ergonomics 37 (4):537-46. doi: 10.1016/j.apergo.2006.04.012.

Widanarko, B., S. Legg, J. Devereux, and M. Stevenson. 2014. "The combined effect of physical, psychosocial/organisational and/or environmental risk factors on the presence of work-related musculoskeletal symptoms and its consequences." Applied Ergonomics 45 (6):1610-21. doi: 10.1016/j.apergo.2014.05.018.

Wilson, J. R. 1994. "Devolving ergonomics: the key to ergonomics managment programmes." Ergonomics 37 (4):579-94.

Wilson, J. R. 2014. "Fundamentals of systems ergonomics/human factors." Applied Ergonomics 45 (1):513. doi: 10.1016/j.apergo.2013.03.021.

Wulff, I. A., R. H. Westgaard, and B. Rasmussen. 1999a. "Ergonomic criteria in large-scale engineering design - I Management by documentation only? Formal organization vs. designers' perceptions." Applied Ergonomics 30 (3):191-205.

Wulff, I. A., R. H. Westgaard, and B. Rasmussen. 1999b. "Ergonomic criteria in large-scale engineering design - II Evaluating and applying requirements in the real world of design." Applied Ergonomics 30 (3):207-21.

Yeow, P. H. P., and R. N. Sen. 2003. "Quality, productivity, occupational health and safety and cost effectiveness of ergonomic improvements in the test workstations of an electronic factory." International Journal of Industrial Ergonomics 32 (3):147-63. doi: 10.1016/s01698141(03)00051-9.

Zimmerman, B. J. 2008. "Goal setting: a key proactive source of academic self-regulation." In Motivation and self-regulated learning: theory, research, and applications, edited by Dale $\mathrm{H}$. Schunk and Barry J. Zimmerman, 267-95. New York: Lawrence Erlbaum Associates. 


\section{APPENDIX}

The following shows the scoring approach, as tested, for the Training function. A summary scoring checklist precedes the rubrics for the 15 associated HF elements. Elements with an 'N/A' label in the checklist denotes those elements deemed not applicable in this iteration of tool development. 


\section{Training Scoring Checklist}

\section{Information:}

\begin{tabular}{|c|c|c|c|}
\hline Human Factors Element & Score & Human Factors Element & Score \\
\hline $\begin{array}{l}\text { HF for performance not only injury } \\
\text { prevention }\end{array}$ & & Continuous review of process & \\
\hline $\begin{array}{l}\text { Cost of injuries/problem related to } \\
\text { source }\end{array}$ & N/A & Review as early as possible & N/A \\
\hline $\begin{array}{l}\text { Total HF cost considered } \\
\text { (direct and indirect) }\end{array}$ & & Multiple people input & N/A \\
\hline $\begin{array}{l}\text { Application reason (e.g. legislated or } \\
\text { culture) }\end{array}$ & & Level of subject matter expert need & \\
\hline Justification for change & & HF two-way communication & N/A \\
\hline HF Guidelines & & Reactive results tracking & N/A \\
\hline HF specific training & & $\begin{array}{l}\text { Lessons learned are logged and acted } \\
\text { upon }\end{array}$ & N/A \\
\hline $\mathrm{HF}$ training timeline and repetition & & Feed forward of information & N/A \\
\hline Employee development & & $\mathrm{HF}$ relevant metrics & \\
\hline $\begin{array}{l}\text { HF in experience delivery (employee's } \\
\text { work deliverables) }\end{array}$ & & $\begin{array}{l}\text { HF connection to traditional metrics } \\
\text { understood }\end{array}$ & N/A \\
\hline $\begin{array}{l}\text { HF includes physical and psychosocial } \\
\text { (employee's workplace) }\end{array}$ & & Strategy integration & \\
\hline $\begin{array}{l}\text { Control and adjustability of work } \\
\text { environment }\end{array}$ & N/A & HF culture & \\
\hline Maintenance for HF problem prevention & N/A & $\mathrm{HF}$ as value promotion & N/A \\
\hline $\begin{array}{l}\text { Feedback questionnaires that investigate } \\
\mathrm{HF}\end{array}$ & & Celebrated - project promotion and ideal & N/A \\
\hline $\begin{array}{l}\text { HF review process } \\
\text { (for HF specific improvement) }\end{array}$ & N/A & $\begin{array}{l}\text { HF considerate hiring and development } \\
\text { package }\end{array}$ & N/A \\
\hline $\begin{array}{l}\text { HF review process applied } \\
\text { (outcome measure) }\end{array}$ & N/A & & \\
\hline
\end{tabular}


HF for performance not only injury prevention (\#1):

\begin{tabular}{l|c}
\hline Level of Human Factors Maturity & Score \\
\hline No consideration of HF for performance in the function of Training - only related to injury. & 0 \\
\hline HF rarely considered for performance in the function of Training. & 1 \\
\hline HF occasionally considered for performance in the function of Training. & 2 \\
\hline HF frequently considered for performance in the function of Training. & 3 \\
\hline $\begin{array}{l}\text { HF considerations in the function of Training always considered for maximising individual } \\
\text { performance and minimising injury risk. }\end{array}$ & 4 \\
\hline
\end{tabular}

Comments:

Total HF cost considered (direct and indirect) (\#3):

\begin{tabular}{l|c}
\hline Level of Human Factors Maturity & Score \\
\hline HF consideration in Training does not include cost of poor HF. & 0 \\
\hline HF consideration in Training occasionally includes direct costs (injury related) of HF. \\
No consideration of indirect costs. & 1 \\
\hline HF consideration in Training always includes direct costs. & 2 \\
No consideration of indirect costs. & 3 \\
\hline HF consideration in Training occasionally includes indirect costs and always includes direct \\
costs.
\end{tabular}

Comments:

Application reason (e.g. legislated or culture) (\#4):

\begin{tabular}{l|c}
\hline Level of Human Factors Maturity & Score \\
\hline No HF applied. & 0 \\
\hline HF should only be applied based on legislative requirements. & 1 \\
\hline HF should only be applied solely for injury prevention. & 2 \\
\hline HF applied for injury prevention and occasionally performance improvement. & 3 \\
\hline HF applied as part of culture of organization - maximize employee performance and well- \\
being.
\end{tabular}

\section{Comments:}


Justification for change (\#5):

\begin{tabular}{|c|c|}
\hline Level of Human Factors Maturity & Score \\
\hline $\begin{array}{l}\text { HF justification for change occurring within Training is at a level required by legislation. } \\
\text { HF justification for change as promoted within Training content is at a level required by } \\
\text { legislation. }\end{array}$ & 0 \\
\hline $\begin{array}{l}\text { HF justification for change occurring within Training is at a level that occasionally exceeds } \\
\text { legislation requirements (injury risk). } \\
\text { HF justification for change promoted within Training is at a level that occasionally exceeds } \\
\text { legislation requirements (injury risk). }\end{array}$ & 1 \\
\hline $\begin{array}{l}\text { HF justification for change occurring within Training is at a level that frequently exceeds } \\
\text { legislation requirements and considers human performance. } \\
\text { HF justification for change promoted within Training is at a level that frequently exceeds } \\
\text { legislation requirements and considers human performance. }\end{array}$ & 2 \\
\hline $\begin{array}{l}\text { HF justification for change occurring within Training is at a level that always exceeds } \\
\text { legislation requirements and occasionally includes cost-benefit/return on investment. } \\
\text { HF justification for change promoted within Training is at a level that always exceeds } \\
\text { legislation requirements and occasionally includes cost-benefit/return on investment. }\end{array}$ & 3 \\
\hline $\begin{array}{l}\text { HF justification for change occurring within Training is at a level that always exceeds } \\
\text { legislation requirements and non-injury, cost-benefit/return on investment. } \\
\text { HF justification for change promoted within Training is at a level that always exceeds } \\
\text { legislation requirements and non-injury, cost-benefit/return on investment. }\end{array}$ & 4 \\
\hline
\end{tabular}

Comments:

HF Guidelines (\#6):

\begin{tabular}{l|c}
\hline Level of Human Factors Maturity & Score \\
\hline HF training does not include HF guidelines. & 0 \\
\hline HF training occasionally includes generic HF guidelines. & 1 \\
\hline HF training frequently includes generic HF guidelines. & 2 \\
\hline HF training occasionally includes organization specific HF guidelines. & 3 \\
\hline HF training frequently includes organization specific HF guidelines. & 4 \\
\hline
\end{tabular}

Comments:

HF specific training (\#7):

\begin{tabular}{l|c}
\hline Level of Human Factors Maturity & Score \\
\hline No component of training considers HF. & 0 \\
\hline Generic HF component exists within health and safety. & 1 \\
\hline Designated HF component to training that is injury focused. & 2 \\
\hline $\begin{array}{l}\text { HF training component includes performance and well-being and content has one of } \\
\text { organization or function specific examples. }\end{array}$ & 3 \\
\hline $\begin{array}{l}\text { HF training component includes performance and well-being and content has organization } \\
\text { and multiple function specific examples. }\end{array}$ & 4 \\
\hline
\end{tabular}

\section{Comments:}


HF training timeline and repetition (\#8):

\begin{tabular}{l|c}
\hline Level of Human Factors Maturity & Score \\
\hline No HF related training completed. & 0 \\
\hline HF related training completed after first year. & 1 \\
HF training is rarely refreshed. & 2 \\
\hline HF training is completed within first year. & 3 \\
HF training is occasionally refreshed. & 3 \\
\hline HF training is completed prior to first required use. & 4 \\
HF training is refreshed every other year. & 4 \\
\hline HF training is completed as part of introductory training. &
\end{tabular}

Comments:

\section{Employee Development (\#9):}

\begin{tabular}{|c|c|}
\hline Level of Human Factors Maturity & Score \\
\hline No technical and personnel development or space for creativity. & 0 \\
\hline $\begin{array}{l}\text { Employee development rarely extends beyond personal work focus and rarely improves } \\
\text { capability and understanding in other aspects of work and life. } \\
\text { Creative space allows employee to think beyond prescribed work for continuous } \\
\text { improvement. }\end{array}$ & 1 \\
\hline $\begin{array}{l}\text { Employee development occasionally extends beyond personal work focus and occasionally } \\
\text { improves capability and understanding in other aspects of work and life. } \\
\text { Creative space allows employee to think beyond prescribed work for continuous } \\
\text { improvement. }\end{array}$ & 2 \\
\hline $\begin{array}{l}\text { Employee development frequently extends beyond personal work focus and frequently } \\
\text { improves capability and understanding in other aspects of work and life. } \\
\text { Creative space allows employee to think beyond prescribed work for continuous } \\
\text { improvement. }\end{array}$ & 3 \\
\hline $\begin{array}{l}\text { Employee development always extends beyond personal work focus and always improves } \\
\text { capability and understanding in other aspects of work and life. } \\
\text { Creative space allows employee to think beyond prescribed work for continuous } \\
\text { improvement. }\end{array}$ & 4 \\
\hline
\end{tabular}

\section{Comments:}

HF in experience delivery (employee's work deliverables) (\#10):

\begin{tabular}{l|c}
\hline Level of Human Factors Maturity & Score \\
\hline Employee's work has no consideration of internal/external customer experience. & 0 \\
\hline Employee's work rarely considers internal/external customer experience. & 1 \\
\hline Employee's work occasionally considers internal/external customer experience. & 2 \\
\hline Employee's work frequently considers internal/external customer experience. & 3 \\
\hline Employee's work always considers internal/external customer experience. & 4 \\
\hline
\end{tabular}

Comments: 
HF includes physical and psychosocial (employee's workplace) (\#11)

\begin{tabular}{l|c}
\hline Level of Human Factors Maturity & Score \\
\hline $\begin{array}{l}\text { HF consideration for the employee includes only some physical aspects and no psychosocial } \\
\text { considerations. }\end{array}$ & 0 \\
\hline $\begin{array}{l}\text { HF consideration for the employee includes many physical aspects and few psychosocial } \\
\text { considerations. }\end{array}$ & 1 \\
\hline $\begin{array}{l}\text { HF consideration for the employee includes physical and psychosocial aspects with } \\
\text { psychosocial findings considered of little value. }\end{array}$ & 3 \\
\hline $\begin{array}{l}\text { HF consideration for the employee includes physical and psychosocial aspects with } \\
\text { psychosocial considerations considered significant in majority of cases. }\end{array}$ & 3 \\
\hline $\begin{array}{l}\text { HF consideration for the employee includes physical and psychosocial considerations } \\
\text { equally. }\end{array}$ & 4 \\
\hline
\end{tabular}

\section{Comments:}

\section{Feedback questionnaires that investigate HF (\#14):}

\begin{tabular}{l|c}
\hline Level of Human Factors Maturity & Score \\
\hline No HF questionnaires review HF training content, procedures and outcomes. & 0 \\
\hline Questionnaires rarely review HF training content, procedures and outcomes. & 1 \\
\hline Questionnaires occasionally review HF training content, procedures and outcomes. & 2 \\
\hline Questionnaires frequently review HF training content, procedures and outcomes. & 3 \\
\hline Questionnaires always review HF training content, procedures and outcomes. & 4 \\
\hline
\end{tabular}

\section{Comments:}

\section{Continuous review of process (\#17):}

\begin{tabular}{l|c}
\hline Level of Human Factors Maturity & Score \\
\hline HF component of training is established and not reviewed. & 0 \\
\hline HF component of training is rarely reviewed for improvement. & 1 \\
\hline HF component of training is occasionally reviewed for improvement. & 2 \\
\hline HF component of training is frequently reviewed for improvement. & 3 \\
\hline HF component of training is always reviewed for improvement. & 4 \\
\hline
\end{tabular}

Comments:

Level of subject matter expert need (\#20):

\begin{tabular}{|c|c|}
\hline Level of Human Factors Maturity & Score \\
\hline HF component of training is completed by external subject matter expert. & 0 \\
\hline $\begin{array}{l}\text { HF component of training is completed jointly by external and internal subject matter } \\
\text { expert. }\end{array}$ & 1 \\
\hline $\begin{array}{l}\text { HF component of training is completed primarily by internal subject matter expert with } \\
\text { external expert recruited as required. }\end{array}$ & 2 \\
\hline HF component of training completed by internal subject matter expert. & 3 \\
\hline HF component of training facilitated by internal subject matter expert as needed. & 4 \\
\hline
\end{tabular}

\section{Comments:}


HF relevant metrics (\#25):

\begin{tabular}{l|c}
\hline Level of Human Factors Maturity & Score \\
\hline No HF relevant metrics exist in Training. & 0 \\
\hline HF Training completion is tracked and not presented. & 1 \\
\hline HF Training completion is tracked and is presented. & 2 \\
\hline HF Training completion rate is tracked and not presented. & 3 \\
HF Training completed is tracked by organization function and not presented. & \\
\hline HF Training completion rate is tracked and is presented. & 4 \\
HF Training completed is tracked by organization function and is presented.
\end{tabular}

Comments:

Strategy integration (\#27):

\begin{tabular}{l|c}
\hline Level of Human Factors Maturity & Score \\
\hline No connection of HF to organization strategy. & 0 \\
No communicated connection of HF to organization strategy. & \\
No HF training connects HF to strategy. & 1 \\
\hline HF rarely connected to organization strategy. & \\
Communications occasionally connects HF to organization strategy. & \\
HF training occasionally connects HF to organization strategy. & 2 \\
\hline HF occasionally connected to organization strategy. & \\
Communications frequently connects HF to organization strategy. & \\
HF training frequently connects HF to organization strategy. & 3 \\
HF frequently connected to organization strategy. & \\
Communications connects HF in strategy decisions to a generic organization outcome. \\
HF training always connects HF to organization strategy with examples of strategy decisions \\
to generic organization outcomes. \\
\hline HF always connected to organization strategy. \\
Communications connects HF in strategy decisions to organization specific outcomes. \\
HF training always connects HF to organization strategy with examples of strategy decisions \\
to organization specific outcomes.
\end{tabular}

\section{Comments:}


HF culture (\#28):

\begin{tabular}{|c|c|}
\hline Level of Human Factors Maturity & Score \\
\hline $\begin{array}{l}\text { HF impact in Training is unknown and not applied. } \\
\text { HF of suppliers and external partners or contractors are not considered important or } \\
\text { relevant. }\end{array}$ & 0 \\
\hline $\begin{array}{l}\text { HF impact in Training is understood by few, rarely applied, and only when mandated. } \\
\text { HF of suppliers and external partners or contractors are rarely considered important or } \\
\text { relevant. }\end{array}$ & 1 \\
\hline $\begin{array}{l}\text { HF impact in Training is understood by some, moderately applied, and only when mandated. } \\
\text { HF of suppliers and external partners or contractors are occasionally considered important } \\
\text { or relevant. }\end{array}$ & 2 \\
\hline $\begin{array}{l}\text { HF impact in Training is understood by most and frequently applied when mandated. } \\
\text { HF of suppliers and external partners or contractors are frequently considered important or } \\
\text { relevant. }\end{array}$ & 3 \\
\hline $\begin{array}{l}\text { HF impact in Training is understood by all and applied without being mandated. } \\
\text { HF of suppliers and external partners or contractors are always considered important or } \\
\text { relevant. }\end{array}$ & 4 \\
\hline
\end{tabular}

\section{Comments:}




\section{Tables}

Table 1. Example rubric for scoring the HF Guidelines element for the Training function.

HF Guidelines (\#6):

\begin{tabular}{l|c}
\hline Level of Human Factors Maturity & Score \\
\hline HF training does not include HF guidelines. & 0 \\
\hline HF training occasionally includes generic HF guidelines. & 1 \\
\hline HF training frequently includes generic HF guidelines. & 2 \\
\hline HF training occasionally includes organization specific HF guidelines. & 3 \\
\hline HF training frequently includes organization specific HF guidelines. & 4 \\
\hline
\end{tabular} Comments: 


\section{Figure Captions}

Figure 1. Framework for the development of the tool, where $n$ functions exist in the organization and $m$ HF elements are contained within a given function.

Figure 2. List of all Organization Functions and the corresponding HF Elements within each function (indicated by an ' $x$ ').

Figure 3. Workshop participant feedback (Average +/- 1 SD; 42 to 45 respondents per item; * denotes significantly different from 4 , a neutral agreement $(p<0.001))$. 